\title{
PENAMBAHAN POLYETHYLENE GLYCOL DIOLEAT PADA PEWARNAAN SARUNG SAMARINDA
}

\author{
Ageng Priatni, ST \\ Baristand Industri Samarinda
}

\begin{abstract}
Silk sarongs Samarinda produced by home industrie in Samarinda were still pale and faded. It was caused by the improper (or incorrect) coloring process usually done by the industries. This research was done to improve the coloring process and to increase the quality of sarong Samarinda. In this research, polyethylene glycol dioleat was added into the dyeing medium and the acidity of the medium was measured. Then the silk was washed and dried under the sunshine. The dried silk was tested for its colour fastnees through washing and ironing process. Results of this research showed that addition of polyethylene glycol dioieat into dyeing medium of sarong Samarinda can improve the quality of polyester material, but it did not produce good result on silk and cotton material.
\end{abstract}

Keywords : sarong Samarinda, polyethylene glycol dioleat; coloring, dyeing medium.

\section{PENDAHULUAN}

$\mathrm{K}$ erajinan tenun sarung Samarinda merupakan khas Kalimantan Timur. Sarung Samarinda yang dihasilkan dibuat dari benang sutera dengan motif dan warna yang khas. Sebagian perajin ada yang menggunakan zat warna alam sebagai pewarna, tetapi dengan hasil yang masih belum memuaskan dan sebagian menggunakan zat warna kimia yang masih impor. Permasalahan yang ada pada industri sarung Samarinda sekarang ini yaitu warna sarung yang dihasilkan mudah luntur dan cepat pudar. Permasalahan ini dikarenakan proses pewarnaan yang dilakukan belum sesuai dengan proses pewarnaan yang benar.

Perkembangan yang pesat dari industri tekstil akan mengakibatkan meningkatnya kebutuhan bahan zat warna yang berguna untuk mewarnai bahan-bahan tekstil. Dewasa ini dipergunakan bermacam-macam jenis zat warna bergantung pada jenis serat yang akan diwarnai, macam warna, ketahanan luntur yang diinginkan, faktor-faktor teknis dan ekonomis lainnya. Di dalam praktik zat warna tekstil tidak digolongkan berdasarkan struktur kimianya, melainkan berdasarkan sifat-sifat pencelupan maupun berdasarkan cara penggunaannya (Sunarto, 2008).

Pencelupan dan pewarnaan pada umumnya terdiri dari tiga tahap: 1) Melarutkan atau mendispersikan zat warna dalam air atau medium lain, 2) Memasukkan bahan tekstil ke dalam larutan sehingga terjadi penyerapan zat warna ke dalam serat, dan 3) Penetrasi atau difusi zat warna dari permukaan ke pusat serat. Penyerapan ini terjadi karena reaksi eksotermik dan kesetimbangan. Baik tidaknya hasil pencelupan atau pewarnaan sangat ditentukan oleh ketiga tahapan pencelupan tersebut. Apabila zat warna terlalu cepat terfiksasi maka kemungkinan diperoleh celupan yang tidak rata. Sebaliknya, apabila zat warna 
memerlukan waktu yang cukup lama untuk fiksasinya dengan tujuan diperoleh waktu yang sesuai dengan yang diharapkan maka diperlukan peningkatan suhu atau penambahan zat-zat pembantu lainnya. Penambahan zat fiksatif ataupun penguat warna adalah hal yang biasa dilakukan pada proses pewarnaan atau pencelupan (Sunarto, 2008). Menurut Anonim, (2009), polyethylene glycol dioleat merupakan salah satu senyawa penguat warna yang banyak digunakan oleh berbagai industri tekstil. Senyawa ini menyerap warna dan menyebabkan warna jadi lebih merata dan tahan lama (pengawet warna). Polyethylene glycol dioleat adalah senyawa turunan oleokimia yang termasuk dalam golongan surfaktan non ionik. Surfaktan non ionik adalah suatu zat afifil yang molekuinya terdiri dari dua bagian yaitu hidrofil dan lifopil. Maka guna perbaikan proses pewarnaan dan mutu Sarung Samarinda dilakukanlah penambahan polyethylene glycol dioleat sebagai penguat/pengawet warna.

\section{BAHAN DAN METODE}

\section{Bahan dan Alat}

Bahan - bahan yang digunakan antara lain Remazol sebagai pewarna tekstil dari perajin sarung Samarinda, kain sutera dari toko tekstil, polyethylene glycol dioleat sebagai penguat warna dari hasil penelitian sebelumnya dan air sebagai pelarut. Peralatan yang digunakan antara lain kompor, panci besar, baskom, gelas ukur, pengaduk dan $\mathrm{pH}$ meter.

\section{Metode}

Kain sutera dipotong dengan ukuran lebar $25 \mathrm{~cm}$ dan panjang 115 $\mathrm{cm}$ kemudian direndam dalam air dengan suhu kamar selama \pm 1 jam. Air sebanyak $5000 \mathrm{ml}$ dipanaskan didalam panci, setelah mencapai suhu $35^{\circ} \mathrm{C}$ (hangat kuku) masukkan 1 gram zat warna remazol. Sebanyak $4 \mathrm{ml}$ PEG Dioleat ditambahkan ke dalam larutan celup, $\mathrm{pH}$ larutan diukur dengan $\mathrm{pH}$ meter. Selanjutnya panaskan air hingga mendidih. Setelah mendidih, kain sutera yang telah direndam dimasukkan ke dalam larutan celup (proses pemasakan). Proses pemasakan dihentikan bila air telah berkurang hingga mencapai 2 (dua) ruas jari $( \pm 30$ menit), kemudian kain diangkat dan ditiriskan sebentar untuk selanjutnya dicuci dengan air. Pencucian dilakukan sampai air bilasan tidak berwarna. Selanjutnya kain sutera dikeringkan dengan cara dijemur dibawah sinar matahari hingga kering. Kain yang telah kering kemudian diuji ketahanan luntur warnanya terhadap pencucian $40^{\circ} \mathrm{C}$ (SNI 08-0285-98) dan penyetrikaan (SNI 08-0290-89). Untuk kontrol, proses pemasakkan dilakukan tanpa penambahan PEG Dioleat. Proses pemasakan dilakukan juga untuk penambahan 8 dan $12 \mathrm{ml}$ PEG Dioleat.

\section{HASIL DAN PEMBAHASAN}

\section{Pewarnaan Kain Sutera}

Tahap pertama dari pewarnaan yaitu melarutkan atau mendispersikan zat warna dalam air. Molekul zat warna dalam larutan akan selalu bergerak dan selanjutnya terdispersi ke dalam pelarut atau air. Pada suhu tinggi gerakan molekul akan menjadi lebih cepat (Sunarto, 2008). Dari tahap pertama pada proses pewarnaan dari penelitian ini, penambahan polyethylene glycol dioleat membuat warna dari larutan celup menjadi lebih tua atau lebih pekat dibandingkan kontrol (tanpa penambahan polyethylene glycol dioleat). Hal ini bisa dilihat pada Gambar 1. 

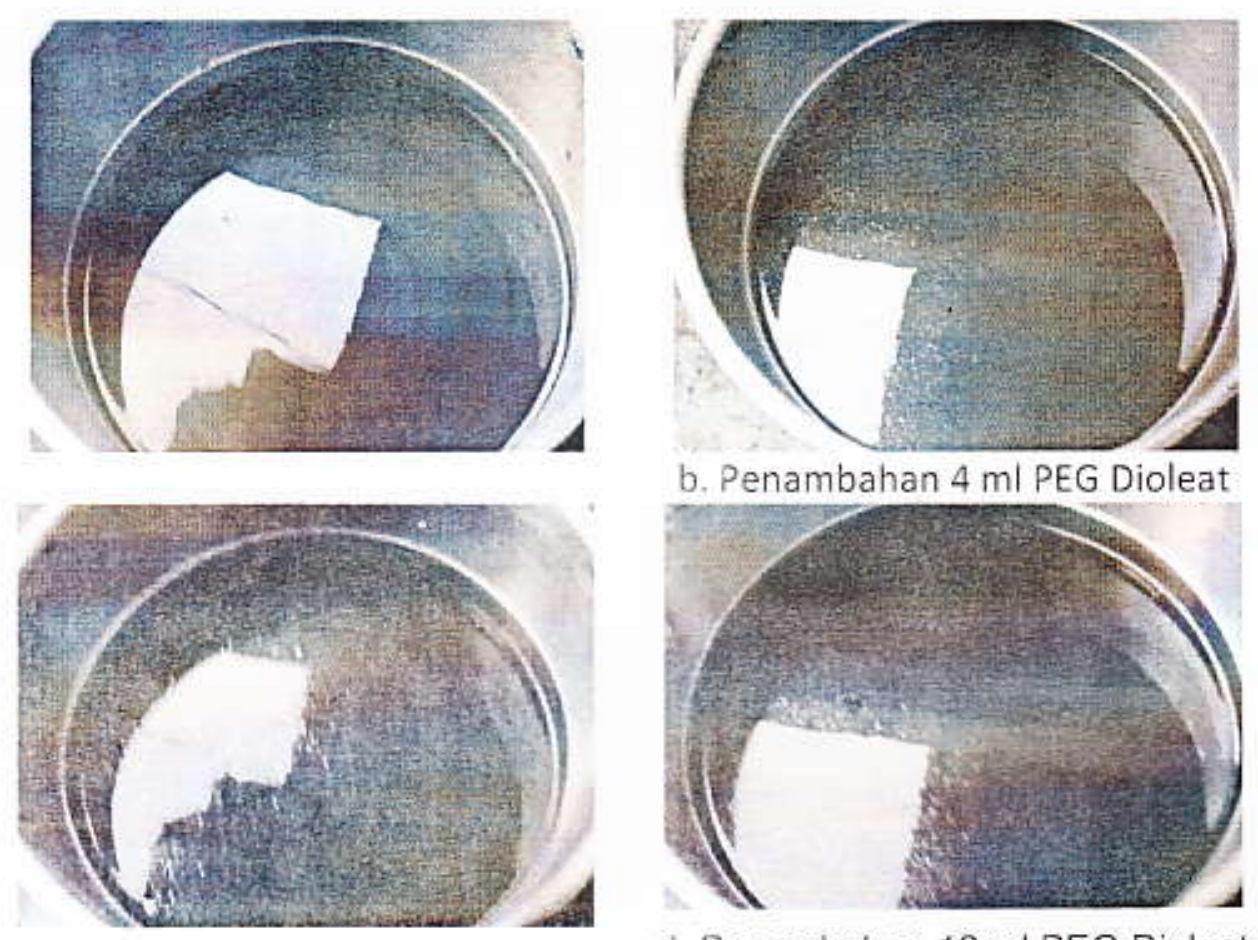

d. Penambahan $12 \mathrm{ml}$ PEG Dioleat

Gambar 1. Warna larutan celup pada keadaan kontrol dan setelah penambahan PEG Dioleat.

Zat warna yang dapat digunakan untuk pencelupan sutera adalah zat warna asam, zat warna komplek logam dan zat warna reaktif (Manurung dkk, 2004). Zat warna yang digunakan oleh pengrajin Sarung Samarinda maupun pada penelitian ini adalah Remazol yang merupakan zat warna reaktif. Menurut Sunarto (2008), macam-macam nama dagang zat warna reaktif antara lain : Procion (I.C.I), Cibacron (Ciba Geigy), Remazol (Hoechst), Levafix (Bayer), Drimarine (Sandoz) dan Primazine (BASF). Zat warna reaktif termasuk golongan zat warna yang larut dalam air. Polyethylene glycol dioleat adalah senyawa turunan oleokimia yang termasuk golongan surfaktan non ionik (Anonim, 2009), Surfaktan adalah suatu zat aktif permukaan. Dengan ditambahkannya surfaktan ke dalam larutan celup mengakibatkan tegangan permukaan antara zat warna dan molekul air menjadi lebih besar sehingga semakin banyak zat warna yang terdispersi atau terlarut dalam air. Besarnya zat warna yang terdispersi ditandai dengan warna yang semakin tua/pekat.

Penambahan polyethylene glycol dioleat pada tahap pertama ini membuat $\mathrm{pH}$ larutan celup menjadi lebih tinggi dibandingkan kontrol, namun penambahan polyethylene glycol dioleat yang bervariasi tersebut tidak berpengaruh banyak terhadap kenaikan $\mathrm{pH}$. Nilai $\mathrm{pH}$ tersebut dapat dilihat pada Tabel 1.

Tabel 1. Nilai pH Pada Tiap-Tiap Perlakuan Dari Proses Pewarnaan

\begin{tabular}{|c|l|c|}
\hline No. & \multicolumn{1}{|c|}{ Perlakuan } & $\mathrm{pH}$ \\
\hline 1 & Kontrol (tanpa penambahan polyethylene glycol dioleat) & 6,20 \\
\hline 2 & Penambahan 4 ml polyethylene glycol dioleat & 7,10 \\
\hline 3 & Penambahan $8 \mathrm{ml}$ polyethylene glycol dioleat & 7,10 \\
\hline 4 & Penambahan $12 \mathrm{ml}$ polyethylene glycol dioleat & 7,11 \\
\hline
\end{tabular}


Di dalam air, zat warna dapat terhidrolisa menurut reaksi berikut :

$$
\mathrm{D}-\mathrm{Cl}+\mathrm{H}_{2} \mathrm{O} \rightarrow \mathrm{D}-\mathrm{OH}+\mathrm{HCl}
$$

\section{Reaksi hidrolisa zat warna oleh air}

Pada tahap ini kemungkinan untuk terjadi reaksi di atas sangat kecil karena reaksi hidrolisa terhadap zat warna banyak terjadi pada $\mathrm{pH}$ tinggi (keadaan basa) (Sunarto, 2008), sedangkan pada keadaan kontrol larutan celup bersifat asam $(\mathrm{pH}$ 6,2), sehingga setelah ditambahkan polyethylene glycol dioleat, reaksi yang terjadi adalah antara polyethylene glycol dioleat dengan air menghasilkan senyawa yang mengandung gugus $\mathrm{OH}^{\circ}$ dan menyebabkan pH larutan celup menjadi lebih tinggi. Adapun reaksi antara polyethylene glycol dioleat dengan air adalah sebagai berikut

$$
\begin{gathered}
\mathrm{C}_{17} \mathrm{H}_{34} \mathrm{COO}-\left(\mathrm{CH}_{2} \mathrm{OCH} \mathrm{H}_{2}\right)-\mathrm{C}_{17} \mathrm{H}_{34} \mathrm{CO}+\mathrm{H}_{2} \mathrm{O} \rightarrow \\
\mathrm{C}_{17} \mathrm{H}_{34} \mathrm{COO}-\left(\mathrm{CH}_{2} \mathrm{OCH}_{2}\right)-\mathrm{OH}+\mathrm{C}_{17} \mathrm{H}_{34} \mathrm{COH}
\end{gathered}
$$

Gambar 3. Reaksi antara polyethylene glycol dioleat dengan Air

Pada tahap kedua pewarnaan, bahan tekstil dimasukkan ke dalam larutan sehingga teriadi penyerapan zat warna ke dalam serat kain. Pada penelitian ini, kain yang akan dimasukkan/dicelupkan direndam terlebih dahulu sehari semalam dengan tujuan agar penyerapan zat warna ke dalam serat kain menjadi lebih mudah. Serat tekstil dalam larutan bersifat negatif pada permukaannya sehingga dalam tahap ini terdapat dua kemungkinan yakni molekul zat warna akan tertarik oleh serat atau tertolak menjauhi serat. Zat warna yang mempunyai tenaga yang cukup besar akan dapat mengatasi gaya-gaya tolak dari permukaan serat, sehingga molekul zat warna tersebut dapat terserap menempel pada permukaan serat. Peristiwa ini disebut adsorpsi (Sunarto, 2008). Hasil penelitian pada tahap ini menunjukkan bahwa terjadi penyerapan zat warna ke dalam serat kain, hal ini dibuktikan dengan berubahnya warna kain yang semula putih menjadi merah sebagaimana dapat dilihat pada gambar 2.

Tahap ketiga dalam pewarnaan adalah penetrasi atau difusi zat warna dari permukaan ke pusat serat. Tahap ketiga ini merupakan proses yang paling lambat sehingga untuk mempersingkat waktu diperlukan peningkatan suhu atau penambahan zat-zat pembantu lainnya (Sunarto, 2008). Pada penelitian ini, untuk mempercepat waktu pemasakkan maka ditambahkan polyethylene glycol dioleat yang merupakan salah satu senyawa penguat warna yang banyak digunakan oleh berbagai industri tekstil.

\section{Uji Ketahanan Luntur Warna}

Dari hasil uji ketahanan luntur warna terhadap pencucian dan penyetrikaan terhadap contoh kain diperoleh hasil rata-rata sebagai terlihat pada Tabel 2. 
Tabel 2. Hasil Uji Ketahanan Luntur Warna Terhadap Pencucian dan Penyetrikaan

\begin{tabular}{|c|c|c|c|c|c|}
\hline \multirow{2}{*}{ No. } & \multirow[t]{2}{*}{ Parameter Uji } & \multicolumn{4}{|c|}{ Hasil Uji } \\
\hline & & Kontrol & $\mathrm{A}$ & $\mathrm{B}$ & C \\
\hline & Ketahanan Luntur Warna Terhadap: & & & & \\
\hline 1. & Pencucian $40^{\circ} \mathrm{C}$ & & & & \\
\hline & a. Perubahan warna (kain sutera) & $2-3$ & $2-3$ & $2-3$ & $2-3$ \\
\hline 2. & Penyetrikaan (Temp. $180^{\circ} \mathrm{C}$ ) & & & & \\
\hline & a. Kering & & & & \\
\hline & - Perubahan warna langsung (kain sutera) & $4-5$ & $4-5$ & $4-5$ & $4-5$ \\
\hline & - Perubahan warna setelah 2 jam & $4-5$ & $4-5$ & $4-5$ & $4-5$ \\
\hline & b. Lembab & & & & \\
\hline & - Perubahan warna langsung (kain sutera) & $4-5$ & $4-5$ & $4-5$ & $4-5$ \\
\hline & - Perubahan warna setelah 2 jam & $4-5$ & 4-5 & $4-5$ & $4-5$ \\
\hline & c. Basah & & & & \\
\hline & - Perubahan warna langsung (kain sutera) & $4-5$ & $4-5$ & $4-5$ & $4-5$ \\
\hline & - Perubahan warna setelah 2 jam & $4-5$ & $4-5$ & $4-5$ & $4-5$ \\
\hline
\end{tabular}

Keterangan :

Kontrol : Tanpa penambahan polyethylene giycol dioleat

A. : Penambahan $4 \mathrm{~m} /$ polyethylene glycol dioleat

B : Penambahan $8 \mathrm{mi}$ polyethylene glycol dioleat

C : Penambahan $12 \mathrm{ml}$ polyethylene glycol dioleat

$5=$ Baik sekall, $4-5=$ Baik, $4=$ Baik, $3-4=$ Cukup baik, $3=$ Cukup, $2-3=$ Kurang baik, $2=$ Kurang,

$1-2=$ Jelek, 1 = Jeiek.

Pada tabel 2 dapat dilihat bahwa penodaan pada poliester untuk ketahanan luntur warna terhadap pencucian baik untuk kontrol maupun untuk contoh yang ditambahkan polyethylene glycol dioleat memberikan nilai yang baik yaitu $4-5$. Zat warna reaktif adalah suatu zat warna yang dapat mengadakan reaksi dengan serat (ikatan kovalen) sehingga zat warna tersebut merupakan bagian dari serat. Karena terjadi reaksi dengan serat selulosa, maka hasil pencelupan zat warna reaktif mempunyai ketahanan luntur yang sangat baik. Demikian pula karena berat molekul kecil maka kilapnya baik (SNI, 1998). Ini berarti bahwa polyethylene giycol dioleat merupakan penguat warna yang cocok untuk pewarnaan dengan zat warna reaktif untuk bahan poliester.

Namun perubahan warna dan penodaan pada kapas untuk ketahanan luntur warna terhadap pencucian baik untuk kontrol maupun untuk contoh yang ditambahkan polyethylene glycol dioleat memberikan nilai yang kurang baik yaitu 2 dan $2-3$, hal ini disebabkan karena bahan sutera dan kapas memiliki pori-pori yang lebih besar dibandingkan poliester sehingga pada saat pencucian, sebagian zat warna yang terikat pada bahan ikut terlarut dan menyebabkan ketahanan luntur warna kurang baik. Ini berarti bahwa polyethylene glycol dioleat bukan merupakan penguat warna yang cocok untuk pewarnaan dengan zat warna reaktif jenis Remozol untuk bahan sutera dan kapas.

Untuk ketahanan luntur warna terhadap penyetrikaan pada keadaan kering, semua parameter untuk semua contoh memberikan nilai yang baik yaitu 4-5. Begitu pula untuk ketahanan luntur warna terhadap penyetrikaan pada keadaan lembab semua memberikan nilai 4 sampai 4-5. Sedangkan ketahanan luntur warna terhadap penyetrikaan pada keadaan basah, memberikan nilai 4-5 (baik) kecuali untuk penodaan pada kapas yang memberikan nilai 3 (cukup). Ini dikarenakan pada keadaan basah, ada zat warna pada kapas yang terdispersi ke dalam air dan ikut teruapkan pada saat penyetrikaan dan pada saat pengeringan diudara sebelum contoh dianalisa.

Pada perlakuan A, B dan C dari pewarnaan di atas, nilai yang diperoleh untuk ketahanan luntur warna terhadap 
pencucian maupun penyetrikaan memberikan nilai yang sama dengan kontrol. Ini dikarenakan volume polyethylene glycol dioleat yang ditambahkan masih terlalu kecil dibandingkan dengan volume larutan celup sehingga polyethylene glycol dioleat yang berfungsi sebagai surfaktan tidak memberikan pengaruh terhadap ketahanan luntur warna. Proses penambahan zat warna dan polyethylene glycol dioleat dilakukan dengan cara melarutkan zat warna terlebih dahulu dengan polyethylene glycol dioleat kemudian ditambah air hangat sedikit sambil diaduk hingga sempurna baru dilarutkan ke dalam air (Sunarto, 2008). Hal ini dimaksudkan agar zat warna nantinya dapat terdispersi dengan baik di dalam air.

\section{KESIMPULAN}

Penambahan Polyethylene glycol dioleat dapat dilakukan pada proses pewarnaan dengan zat warna reaktif untuk bahan poliéster, sedangkan untuk bahan sutera dan kapas tidak memberikan pengaruh sehingga penambahan Polyethylene glycol dioleat belum dapat meningkatkan kualitas/mutu dari Sarung Samarinda yang berbahan sutera.

\section{DAFTAR PUSTAKA}

Anonim, 2009, http://www.kimialipi.net/index.php?pilihan=litbang\& kunci $=\&$ kategori $=5 \& \mathrm{id}=2$, diakses tgl. 03 Maret 2009.

Manurung, R., Hasibuan, R \& Irvan, 2004, "Perombakan Zat Warna Azo Reaktif Secara Anaerob Aerob", Fakultas Teknik, Jurusan Teknik Kimia, Universitas Sumatera Utara

SNI, 1989, SNI 08-0290-89, "Cara Uji Tahan Luntur Warna Terhadap Penyetrikaan", Badan Standardisasi Nasional, Jakarta

SNI, 1998, SNI 08-0285-98, " Cara Uji Tahan Luntur Warna Terhadap Pencucian", Badan Standardisasi Nasional, Jakarta.

Sunarto, 2008, "Teknik Pencelupan dan Pencapan, untuk SMK", Jilid 2. Buku Sekolah Elektronik, Direktorat Pembinaan SMK, Direktorat Jenderal Manajemen Pendidikan dasar \& Menengah, Departemen Pendidikan Nasional., diakses tgl 2 Desember 2009. 